\title{
Cantharidin inhibits cell proliferation and promotes apoptosis in tongue squamous cell carcinoma through suppression of miR-214 and regulation of $\mathrm{p53}$ and $\mathrm{Bcl}-2 / \mathrm{Bax}$
}

\author{
XIAOGUANG TIAN ${ }^{1,2^{*}}$, GUANG ZENG ${ }^{3 *}, \mathrm{XI} \mathrm{LI}^{4}$, ZIZHONG WU $^{2}$ and LEI WANG ${ }^{1}$ \\ ${ }^{1}$ State Key Laboratory of Military Stomatology, Department of Orthodontics, School of Stomatology, The Fourth Military \\ Medical University, Xi'an, Shaanxi 710038; ${ }^{2}$ Department of Oral and Maxillofacial Surgery, The 88th Hospital of PLA, \\ Tai'an, Shandong 271000; ${ }^{3}$ Department of Plastic and Burn Surgery, Tangdu Hospital, The Fourth Military Medical University, \\ Xi'an, Shaanxi 710038; ${ }^{4}$ Hospital of Chongming Air Force Field, Shanghai 202150, P.R. China
}

Received January 8, 2015; Accepted March 9, 2015

DOI: 10.3892/or.2015.3942

\begin{abstract}
Cantharidin, a type of terpenoid, is a chemical compount secreted by the blister beetle or Mylabris phelarata pallas of the Meloidae family. Cantharidin is known to have good antitumor activity. The present study aimed to investigate the anticancer effect of cantharidin and its possible underlying mechanism using tongue squamous cell carcinoma (TSCC) TCA8113 cells. TCA8113 cells were treated with various concentrations of cantharidin, and the cell viability and cytotoxicity were assessed using MTT and LDH assays, respectively. Flow cytometry was conducted to examine cell apoptosis and colorimetric protease assay was performed to analyze caspase-9/3 activities in TCA8113 cells. qPCR and western blot analysis were used to investigate microRNA-214 (miR-214) expression, as well as the expression of p53, Bcl-2 and Bax proteins in TCA8113 cells. miR-214 and anti-miR-214 were transfected with mimics to examine whether miR-214 expression regulated the anticancer effect of cantharidin on TCA8113 cells and p53, Bcl-2 and Bax protein expression. The anticancer effect of cantharidin significantly inhibited cell proliferation and increased cytotoxicity of TSCC Tca8113 cells in a dose- and time-dependent manner. In addition, cantharidin induced cell apoptosis and activated caspase9/3 activities of TSCC Tca8113 cells. Cantharidin markedly weakened miR-214 expression level, activated p53 protein expression, and suppressed the Bcl-2/Bax signaling pathway in Tca8113 cells. Downregulation of miR-214 increased p53 protein expression and decreased the $\mathrm{Bcl}-2 / \mathrm{Bax}$ signaling
\end{abstract}

Correspondence to: Dr Lei Wang, State Key Laboratory of Military Stomatology, Department of Orthodontics, School of Stomatology, The Fourth Military Medical University, Xi'an, Shaanxi 710038, P.R. China E-mail: leiwang2014kq@163.com

${ }^{*}$ Contributed equally

Key words: cantharidin, tongue squamous cell carcinoma, miR-214, $\mathrm{p} 53, \mathrm{Bcl}-2 / \mathrm{Bax}$ pathway of TSCC Tca8113 cells. However, the overexpression of miR-214 reduced the anticancer effect of cantharidin on the proliferation and apoptosis of TSCC Tca8113 cells, inhibited p53 protein expression, and increased the Bcl-2/Bax signaling pathway. The results suggested that cantharidin is a potential anticancer drug that can be used to regulate the proliferation and apoptosis of human TSCC Tca8113 cells. Additionally, its mechanism may partially be associated with the downregulation of miR-214, upregulation of $\mathrm{p} 53$ protein expression and suppression of the Bcl-2/Bax signaling pathway.

\section{Introduction}

The incidence of oral cancer accounts for $\sim 5 \%$ of all the malignant tumors of body, and the 5-year survival rate is $\sim 64 \%$ (1). The incidence of oral cancer in China is 5-6/100.000 individuals. Squamous epithelial cancer is most common in oral and maxillofacial malignancies, accounting for $\sim 80 \%$ of oral and maxillofacial tumors (2). Tongue squamous cell carcinoma (TSCC) has the highest incidence of oral cancers with cervical lymph-node metastasis occurring in early stage, rendering it an early event for the development of TSCC. Thus, it is particularly important to identify clinical treatment as well as prediction of recurrence and prognosis (3).

Recent findings have shown that there is an abnormality of microRNA (miR) expression in a variety of tumors. This influences the biological behavior, such as proliferation, apoptosis, differentiation, movement, invasion, metastasis and angiogenesis, of tumor cells through the regulation of downstream target genes and plays a role in oncogenes or tumor-suppressor genes, which are involved in tumorigenesis and the development of tumors, a multi-step process $(4,5)$. Recent studies have found miR-214 is associated with a variety of malignancies, which plays a tumor suppressor or tumor promotion effect through multiple signal transduction pathways. The knockdown of miR-214 which promotes apoptosis and inhibits proliferation in TSCC Tca8113 cells (6), and in nasopharyngeal (7) and hepatocellular carcinoma (8), has been previously reported.

The $p 53$ gene is considered to be associated with cancer in humans. Proliferating cell nuclear antigen, also known as 
cyclin, is an auxiliary protein of DNA polymerase $\delta$, involved in the regulation of DNA synthesis and closely associated with cell cycle proliferation (9). Qi and Zhang showed that alisertib induced apoptosis of human TSCC by activation of the p53 pathway (10). Yasumoto et al reported that apoptosisrelated gene expression after hyperthermia harbors wild- or mutated-type p53 in human TSCC (11). Nagler et al identified that the possible biological significance of markers is an independent role for p53 in TSCC (12). Tumor occurrence is associated with hindered apoptosis. The Bcl-2/Bax gene is important for the inhibition of apoptosis, and upregulation of the Bcl-2/Bax signal may play an important role in the occurrence and development of TSCC Tca8113 $(13,14)$. Xie et al reported that the $\mathrm{Bcl}-2 / \mathrm{Bax}$ expression ratio has a prognostic value in TSCC (15).

Cantharidin is an active pharmaceutical ingredient for cantharide, which has a good effect on malignant tumors such as liver (16), esophageal (17), lung (18) and gastric (19) cancer, and has been used in clinical treatment of cancer over a long period of time. As reported, cantharidin induces tumor cell apoptosis. However, the estimated anticancer effect of cantharidin on cell proliferation and apoptosis of human TSCC remains to be determined. Thus, we investigated the anticancer effect of cantharidin on the behavior of human TSCC TCA8113 cells and investigated the molecular mechanisms related involved in this activity.

\section{Materials and methods}

Reagents and instruments. The cantharidin chemical structure (Sigma-Aldrich, St. Louis, MO, USA), with a purity of $\geq 95 \%$ is shown in Fig. 1. Dulbecco's modified Eagle's medium (DMEM) was purchased from Invitrogen Life Technologies (Carlsbad, CA, USA). Fetal bovine serum (FBS) was purchased from HyClone, Invitrogen Co. (Australia). 3.3-(4,5-Dimethylthiazol2-yl)-2,5-diphenyltetrazolium bromide (MTT) was purchased from Sigma-Aldrich. Annexin V-fluorescein isothiocyanate (V-FITC)/propidium iodide (PI) double staining kits were purchased from Sigma-Aldrich.

Cell line and culture conditions. Human TSCC TCA8113 cells were obtained from the Shanghai Usea Biotech Company (Shanghai, China). TCA8113 cells were cultured in DMEM containing 10\% FBS, 1\% penicillin/streptomycin (Invitrogen Life Technologies), and maintained at $37^{\circ} \mathrm{C}$ in a humidified atmosphere of $5 \% \mathrm{CO}_{2}$.

Detection of cell proliferation by MTT assay. Proliferation of TCA8113 cells was screened by MTT colorimetric assay. Briefly, TCA8113 cells $\left(2 \times 10^{3}\right.$ cells/well $)$ were seeded in 96 -well plates and treated with cantharidin $(0,2.5,5,10,20$, 40 and $80 \mu \mathrm{M}$ ) for 24,48 or $72 \mathrm{~h}$ following treatment, respectively. TCA8113 cells were added with $20 \mu 1$ MTT $(5 \mathrm{mg} / \mathrm{ml})$ and the cells were cultured for an additional $4 \mathrm{~h}$. DMSO was added to each well and agitated for $20 \mathrm{~min}$. The absorbance was measured with Multiskan Spectrum microplate reader (Thermo Fisher Scientific, Waltham, MA, USA) at $490 \mathrm{~nm}$.

Detection of cell cytotoxicity by lactate dehydrogenase (LDH) assay. Proliferation of TCA8113 cells was screened by LDH

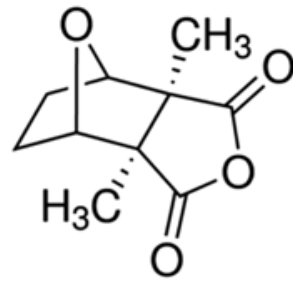

Figure 1. The chemical structure of cantharidin.

assay. Briefly, TCA8113 cells $\left(2 \times 10^{3}\right.$ cells/well) were seeded in 96-well plates and treated with cantharidin $(10,20$ and $40 \mu \mathrm{M})$ for $48 \mathrm{~h}$ following treatment. Each well was added with $100 \mu \mathrm{l}$ LDH solution and incubated at room temperature for $30 \mathrm{~min}$. The absorbance was read at $490 \mathrm{~nm}$ using a multiwell spectrophotometer (XL-818; Bio-Tek, Winooski, VT, USA).

Detection of cell apoptosis by flow cytometry. Apoptosis of TCA8113 cells was analyzed by flow cytometry. Briefly, TCA8113 cells $\left(2 \times 10^{6}\right.$ cells/well $)$ were seeded in 6-well plates and treated with cantharidin $(10,20$ and $40 \mu \mathrm{M})$ for $48 \mathrm{~h}$ following treatment. TCA8113 cells were collected and washed twice with ice-cold phosphate-buffered saline (PBS). TCA8113 cells $\left(1 \times 10^{6}\right.$ cells $\left./ \mathrm{ml}\right)$ were resuspended with binding buffer according to the manufacturer's instructions (Sigma-Aldrich). Annexin V-FITC $(10 \mu \mathrm{l})$ was added into TCA8113 cells and stained for $30 \mathrm{~min}$ in the dark. The samples were immediately analyzed by flow cytometry.

Detection of caspase-9 and -3 activities by colorimetric protease assay. Apoptosis of TCA8113 cells was analyzed using flow cytometry. Briefly, TCA8113 cells $\left(2 \times 10^{6}\right.$ cells/well) were seeded in 6-well plates and treated with cantharidin (10, 20 and $40 \mu \mathrm{M}$ ) for $48 \mathrm{~h}$ following treatment. TCA8113 cells were washed with twice PBS. The cells were lysed on ice in a buffer and cultured for $30 \mathrm{~min}$. The total proteins were determined using a BSA kit (Pierce, Rockford, IL, USA). Equal protein was mixed with reaction buffer (Ac-DEVD-pNA for caspase-3, Ac-LEHD-pNA for caspase-9) and incubated at $37^{\circ} \mathrm{C}$ for $2 \mathrm{~h}$ in the dark. Caspase-3/9 activity was measured at an absorbance of $405 \mathrm{~nm}$.

Detection of miR-214 expression by quantitative polymerase chain reaction $(q P C R)$. miR-214 expression levels were measured with qPCR. Briefly, TCA8113 cells $\left(2 \times 10^{6}\right.$ cells/well) were seeded in 6-well plates and treated with cantharidin (10, 20 and $40 \mu \mathrm{M}$ ) for $48 \mathrm{~h}$ following treatment. Total RNA was isolated from renal tissues using TRIzol, according to the manufacturer's instructions (Invitrogen, Chicago, IL, USA). cDNAs were produced and detected using the TaqMan 7900 (ABI) Real-Time PCR system, according to the manufacturer's protovarian (Qiagen, Valencia, CA, USA). The expression of miR-214 was measured using a SYBR-Green kit, according to the manufacturer's instructions (Qiagen). The primers were compound and purchased from BeastBio Co., Ltd. (Shanghai, China). miR-214-F, 5'-AGCATAATACAGCAGGCACA GAC-3' and miR-214-R 5'-AAAGGTTGTTCTCCACTC TCTCAC-3'; U6-F, 5'-CGCTTCGGCAGCACATATACTA-3' and U6-R, 5'-CGCTTCACGAATTTGCGTGTCA. 


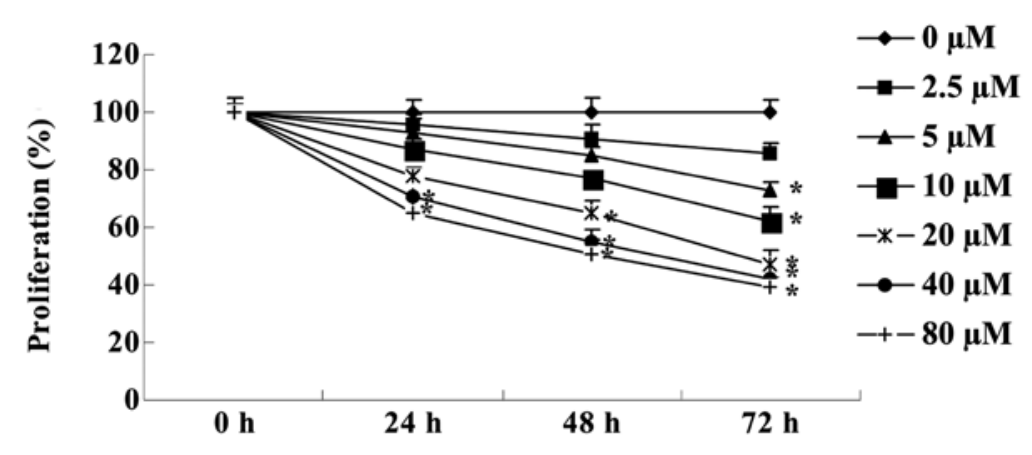

Figure 2. Cantharidin inhibits the proliferation of TSCC Tca8113 cell. "P<0.01 compared with $0 \mu \mathrm{M}$ cantharidin-treatment group. TSCC, tongue squamous cell carcinoma.

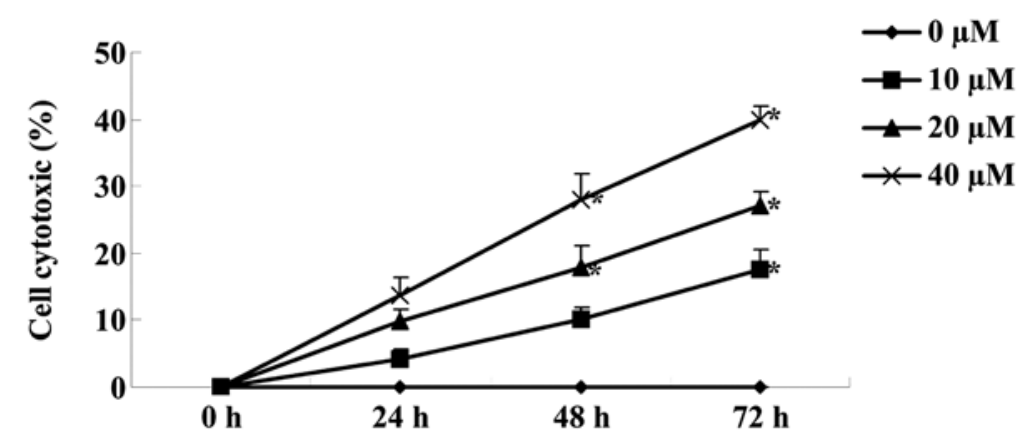

Figure 3. Cantharidin promotes the cytotoxicity of TSCC Tca8113 cells. " $\mathrm{P}<0.01$ compared with $0 \mu \mathrm{M}$ cantharidin-treatment group. TSCC, tongue squamous cell carcinoma.

Detection of $\mathrm{p53}, \mathrm{Bcl}-2$ and Bax protein expression by western blotting. p53 and Bax protein expression levels were detected with western blotting. Briefly, TCA8113 cells ( $2 \times 10^{6}$ cells/well) were seeded in 6 -well plates and treated with cantharidin $(10,20$ and $40 \mu \mathrm{M})$ for $48 \mathrm{~h}$ following treatment. TCA 8113 cells were washed with twice PBS. The cells were lysed on ice in a buffer and cultured for $30 \mathrm{~min}$. The lysed solution was centrifuged at $12,000 \mathrm{x} \mathrm{g}$ for $10 \mathrm{~min}$ at $4^{\circ} \mathrm{C}$. The total proteins were determined using a BSA kit. Equivalent amounts of protein were separated by $10 \%$ SDS-PAGE and then transferred to polyvinylidene difluoride membranes (Millipore, Billerica, MA, USA). The membranes were blocked with Tris-buffered saline (TBS) containing $5 \% \mathrm{w} / \mathrm{v}$ non-fat milk to block non-specific binding sites. The membranes were blocked and incubated overnight with anti-p53 (1:1,000), anti-Bcl-2 (1:1,000), anti-Bax $(1: 1,500)$ (all from Santa Cruz Biotechnology, Inc., Dallas, TX, USA) and anti- $\beta$-actin (1:500; Sangon Biotech, Shanghai, China) overnight at $4^{\circ} \mathrm{C}$. The membranes were then incubated with IgG-conjugated goat anti-rabbit secondary antibodies at room temperature for $2 \mathrm{~h}$ using enhanced chemiluminescent reagents (Tiangen, Beijing, China) and exposed to X-ray film.

Transfection of miR-214 and anti-miR-214. The TCA8113 cells $\left(2 \times 10^{6}\right.$ cells/well) were seeded in 6 -well plates $24 \mathrm{~h}$ prior to transfection. miR-214 inhibitors and mimics were established by BeastBio Co., Ltd. miR-214 inhibitors (10 nM duplex/well) and miR-214 mimics (10 nM duplex/well) were performed using Lipofectamine 2000 (Invitrogen Life Technologies).
Statistical analysis. Analysis of variance (ANOVA) or Student's t-test was performed with SPSS software. Data were presented as mean $\pm \mathrm{SD}$. $\mathrm{P}<0.05$ was considered to indicate a statistically significant result.

\section{Results}

Cantharidin inhibits the proliferation of TSCC Tca8113 cells. To confirm the effect of cantharidin on the proliferation of TSCC Tca8113 cells, an MTT assay was used to measure the growth of Tca8113 cella. The results showed that cantharidin inhibited the proliferation of Tca8113 cells in a dose- and timedependent manner (Fig. 2). After $72 \mathrm{~h}$, the anticancer effect of cantharidin $(5,10,20,40$ and $80 \mu \mathrm{M})$ markedly inhibited the proliferation of Tca8113 cells. After $48 \mathrm{~h}$, treatment with cantharidin $(20,40$ and $80 \mu \mathrm{M})$ significantly inhibited the proliferation of Tca8113 cells. Treatment with cantharidin (40 and $80 \mu \mathrm{M}$ ) significantly inhibited the proliferation of Tca8113 cells for $24 \mathrm{~h}$.

Cantharidin promotes cytotoxicity of TSCC Tca8113 cells. An $\mathrm{LDH}$ assay was used to investigate the effect of cantharidin on the cytotoxicity of TSCC Tca8113 cells treated with $0,10,20$ and $40 \mu \mathrm{M}$ cantharidin for $48 \mathrm{~h}$. In the Tca8113 cells treated with $0,10,20$ and $40 \mu \mathrm{M}$ cantharidin, cantharidin increased the cytotoxicity of Tca8113 cells in a dose- and timedependent manner (Fig. 3). After 48 and 72 h, cantharidin (20 and $40 \mu \mathrm{M})$ notably increased the cytotoxicity of Tca 8113 cells (Fig. 3). 


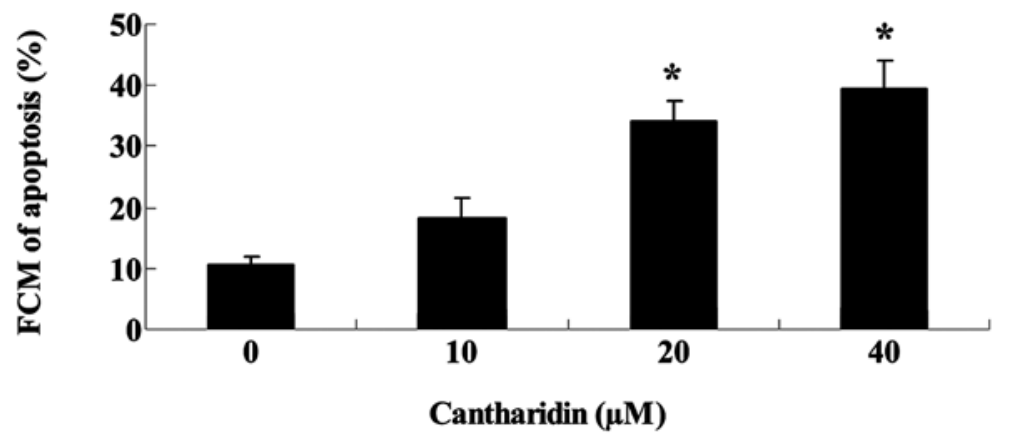

Figure 4. Cantharidin promotes the cytotoxicity of TSCC Tca8113 cells. " $\mathrm{P}<0.01$ compared with $0 \mu \mathrm{M}$ cantharidin-treatment group. TSCC, tongue squamous cell carcinoma.

A

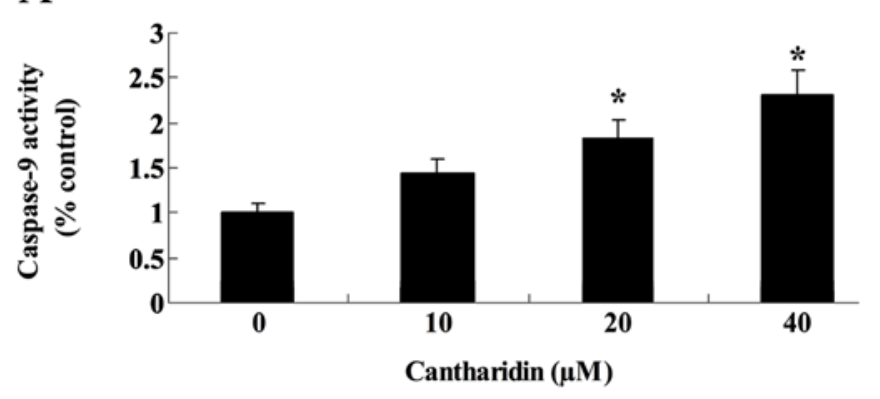

$\mathrm{B}$

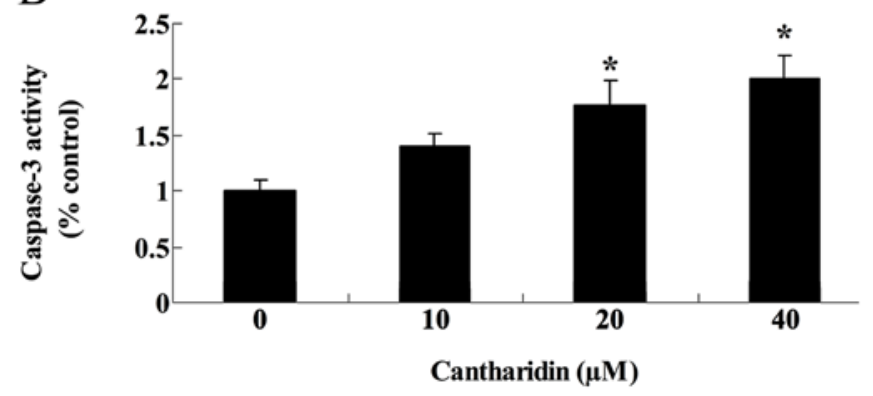

Figure 5. Cantharidin induced caspase- 9 and -3 activities of TSCC Tca8113 cells. Cantharidin induced (A) caspase-9 and (B) caspase-3 activities of TSCC Tca8113 cells. * $\mathrm{P}<0.01$ compared with $0 \mu \mathrm{M}$ cantharidin-treatment group. TSCC, tongue squamous cell carcinoma.

Cantharidin promotes apoptosis of TSCC Tca8113 cells. To investigate whether cantharidin induced inhibition of TSCC Tca8113 cells through cell apoptotic pathways, apoptosis of Tca8113 cells was measured by flow cytometry. After $48 \mathrm{~h}$, treatment with cantharidin $(20$ and $40 \mu \mathrm{M})$ significantly promoted the apoptosis of Tca8113 cells (Fig. 4).

Cantharidin induces caspase-9 and -3 activities of TSCC Tca8113 cells. The possible signaling pathways through which cantharidin induced apoptosis in Tca 8113 cells were investigated to detect caspase- 9 and -3 activities of Tca8113 cells. Fig. 5 shows that caspase- 9 and -3 activities of Tca8113 cells were markedly increased by treatment with cantharidin $(20$ and $40 \mu \mathrm{M})$.

Cantharidin suppresses miR-214 expression of TSCC Tca8113 cell. To investigate the functional role of miR-214 expression in TSCC Tca8113 cell, we carried out miR-214 expression of Tca8113 cells using qPCR. miR-214 expression level was markedly downregulated by treatment with cantharidin (20 and $40 \mu \mathrm{M}$ ) in Tca8113 cells (Fig. 6).

Cantharidin increases p53 protein expression of TSCC Tca8113 cells. The underlying signaling pathways through which cantharidin regulated the proliferation and apoptosis of TSCC Tca8113 cells were examined, and p53 protein expression of Tca8113 cells was examined using western blotting. After $48 \mathrm{~h}$, treatment with cantharidin $(20$ and $40 \mu \mathrm{M})$ repaired and markedly increased p53 protein expression of Tca8113 cells (Fig. 7A and B).

Cantharidin adjusts Bcl-2/Bax protein expression of TSCC Tca8113 cells. To investigate the potential connection between $\mathrm{Bcl}-2 / \mathrm{Bax}$ protein expression and the potential anticancer effect of cantharidin on TSCC Tca8113 cells, western blotting was used to analyze $\mathrm{Bcl}-2 / \mathrm{Bax}$ protein expression in Tca8113 cells. After $48 \mathrm{~h}, \mathrm{Bcl}-2$ protein expression was suppressed by treatment with cantharidin $(20$ and $40 \mu \mathrm{M})$ in Tca8113 cells (Fig. 8A and B). By contrast, the Bax protein expression of Tca8113 cells was activated by treatment with cantharidin $(20$ and $40 \mu \mathrm{M}$ ) for $48 \mathrm{~h}$ (Fig. 8C and D).

Anti-miR-214 and expression of p53 and Bcl-2/Bax proteins in TSCC Tca8113 cells. To investigate the potential connection between miR-214 silencing and the potential anticancer effect of cantharidin on TSCC Tca8113 cells, miR-21 inhibitors were transfected into Tca8113 cells to detect the p53 and Bcl-2/Bax protein expression in Tca8113 cells. Firstly, miR-21 expression of Tca8113 cells were significantly inhibited by miR-21 inhibitors (Fig. 9A). p53 protein expression of Tca8113 cells was subsequently increased by miR-21 inhibitors (Fig. 9B and C). Bcl-2 protein expression was attenuated and Bax protein expression was enhanced following miR-21 transfection (Fig. 9D and G). These results suggest that miR-214 inhibition regulated $\mathrm{p} 53$ and $\mathrm{Bcl}-2 / \mathrm{Bax}$ expression in Tca8113 cells. 


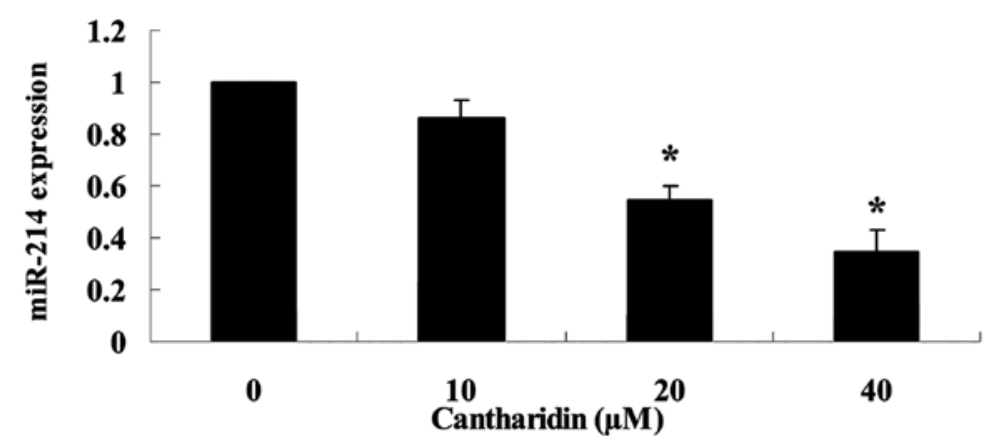

Figure 6. Cantharidin suppressed miR-214 expression of TSCC Tca8113 cells. " $\mathrm{P}<0.01$ compared with $0 \mu \mathrm{M}$ cantharidin treatment group. TSCC, tongue squamous cell carcinoma.

A

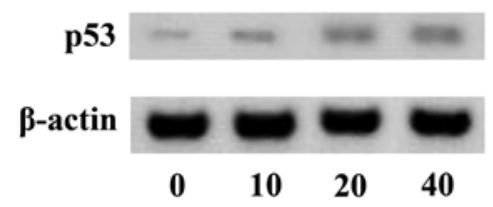

Cantharidin $(\mu \mathrm{M})$
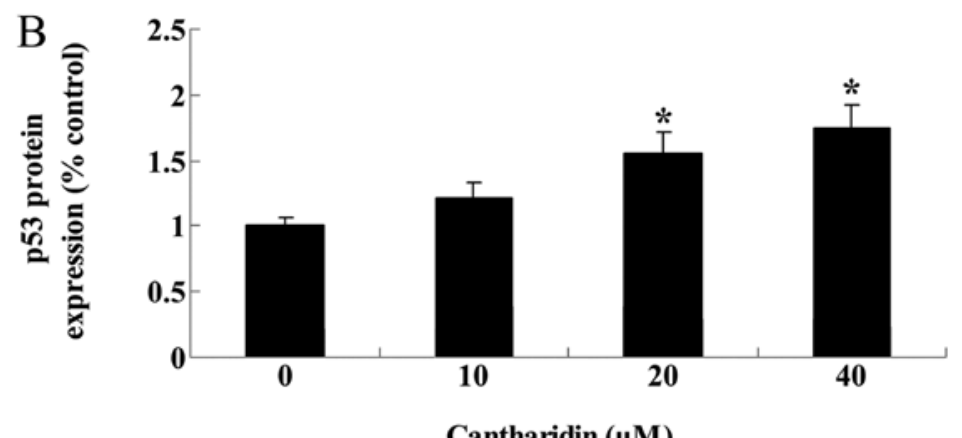

Figure 7. Cantharidin increases p53 protein expression of TSCC Tca8113 cells. (A) The effects of cantharidin on p53 protein expression by western blotting assays. (B) Statistical analysis of p53 protein expression levels of TSCC Tca8113 cells. "P $<0.01$ compared with $0 \mu \mathrm{M}$ cantharidin treatment group. TSCC, tongue squamous cell carcinoma.

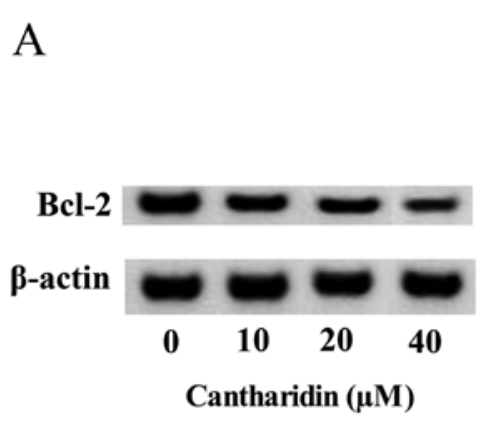

$\mathrm{C}$

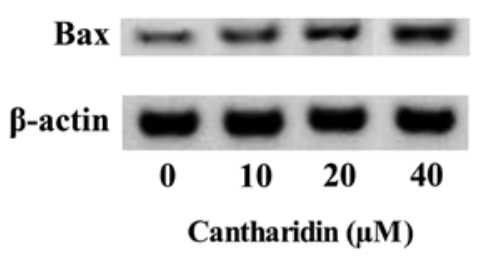

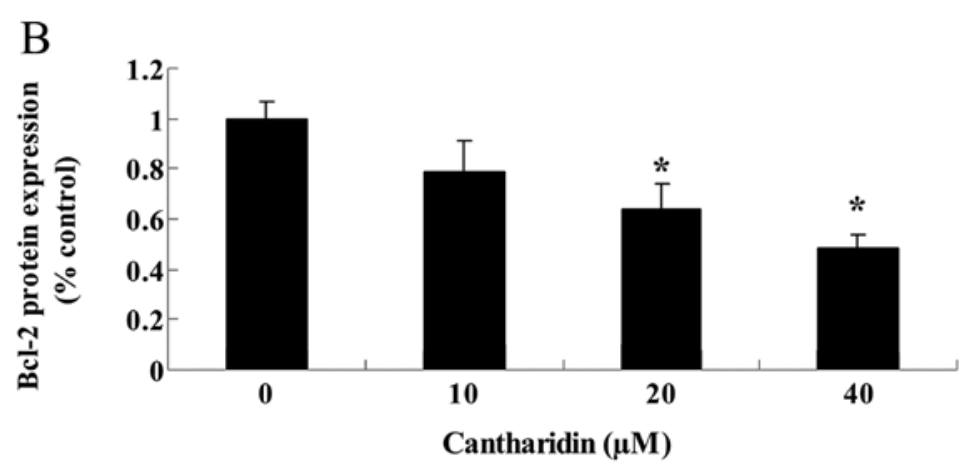

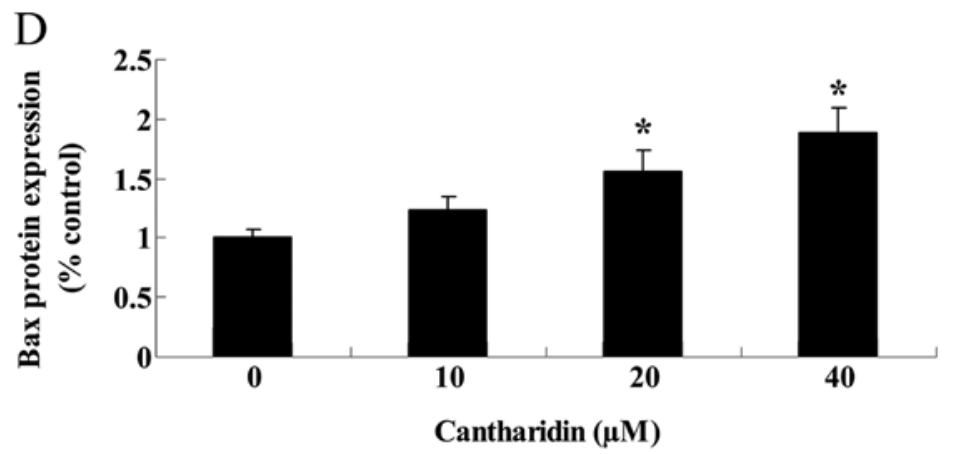

Figure 8. Cantharidin adjusts Bcl-2/Bax protein expressions of TSCC Tca8113 cell. (A and C) The effects of cantharidin on Bcl-2/Bax protein expression by western blot assays. (B and D) Statistical analysis of Bcl-2/Bax protein expression levels of TSCC Tca8113 cells. " $\mathrm{P}<0.01$ compared with $0 \mu \mathrm{M}$ cantharidin treatment group. TSCC, tongue squamous cell carcinoma.

Overexpression of miR-214 and the anticancer effect of cantharidin on TSCC Tca8113 cells. To assess the potential connection between miR-214 overexpression and the anticancer effect of cantharidin on TSCC Tca8113 cells, miR-214 


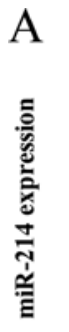

A

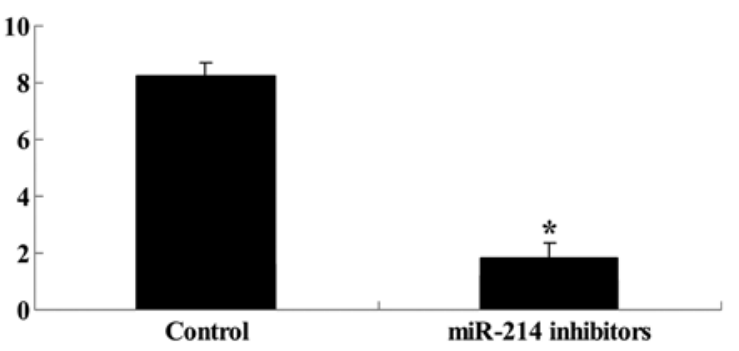

$\mathrm{C}$

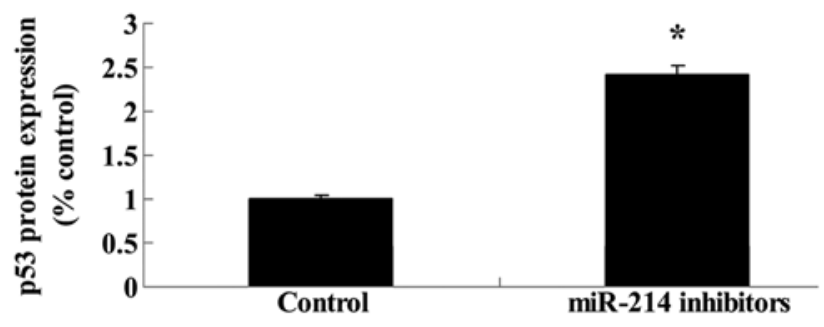

$\mathrm{E}$

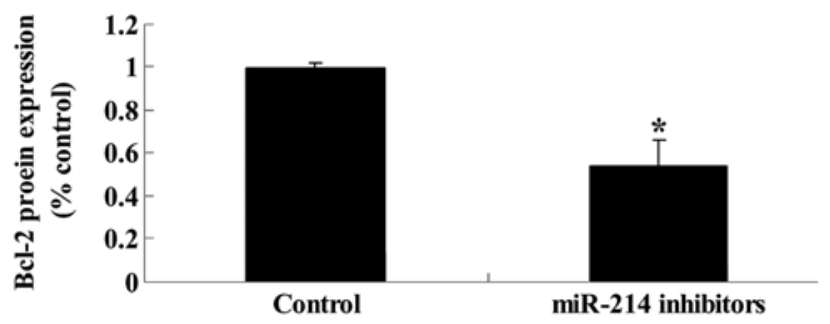

$\mathrm{G}$

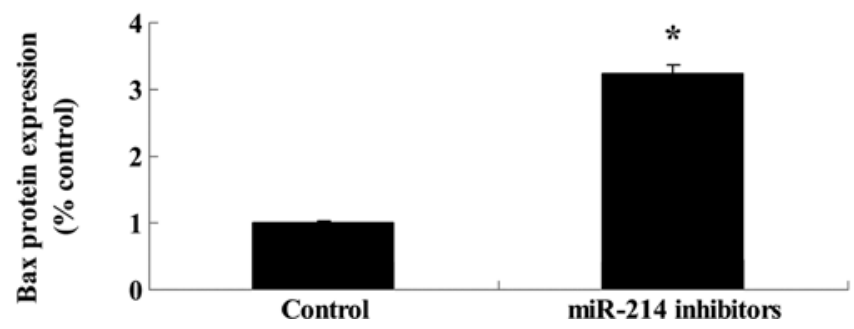

$\mathrm{B}$

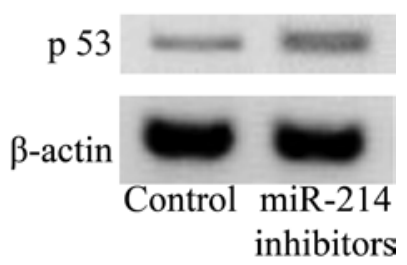

D

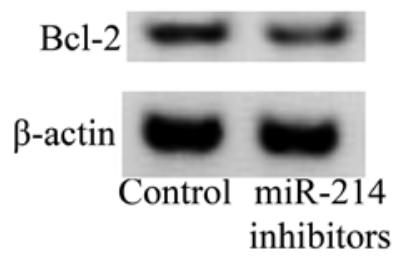

$\mathrm{F}$

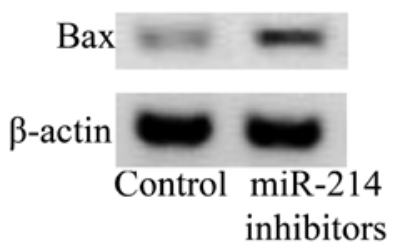

Figure 9. Anti-miR-214 and expression of p53 and Bcl-2/Bax protein expression of TSCC Tca8113 cells. miR-214 inhibitors inhibited (A) miR-214 expression. (B, D and F) p53, Bcl-2 and Bax protein expression by western blot analysis. (C, E and G) Statistical analysis of p53, Bcl-2 and Bax protein expression levels of TSCC Tca8113 cells. ${ }^{*} \mathrm{P}<0.01$ compared with $0 \mu \mathrm{M}$ cantharidin treatment group. TSCC, tongue squamous cell carcinoma.

mimics were transfected into Tca8113 cells. The result in Fig. 10A shows that miR-214 mimics significantly increased the expression levels of miR-214 in Tca8113 cells. However, miR-214 mimics reversed the potential anticancer effect of cantharidin on the proliferation, thereby reducing caspase-3 activation in Tca8113 cells (Fig. 10B and C). Notably, p53 and Bax protein expression of Tca8113 cells were weakened by miR-214 overexpression (Fig. 10D and E, and H and I). miR-214 overexpression increased Bcl-2 protein expression of Tca8113 cells (Fig. 10F and G). The results suggested that overexpression of miR-214 reduces the anticancer effect of cantharidin on TSCC Tca8113 cells regulated by p53 and Bcl-2/Bax expression in Tca8113 cells.

\section{Discussion}

Oral cancer refers to oral and maxillofacial malignancies, of which the majority are squamous epithelial cancer, including tongue, buccal, gum, palate, lip and jaw bone cancer, oral floor carcinoma and oropharyngeal cancer (3). TSCC is a common oral cancer. The occurrence and development of cancer is a multi-step process with multi-gene mutations, while tumor growth and metabolism are associated with growth scores and self-programmed death (20). Autophagy, as a form of programmed death, is a highly conserved cellular behavior, closely associated with cell growth and proliferation, as well as the tumor development process (21). In the present study, 


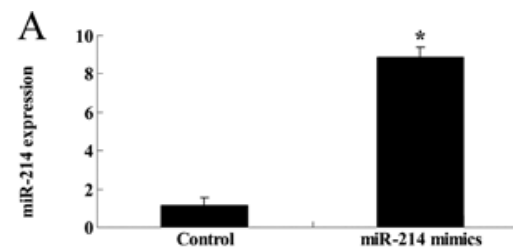

D

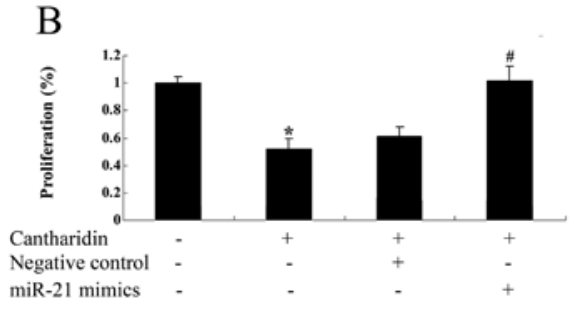

E

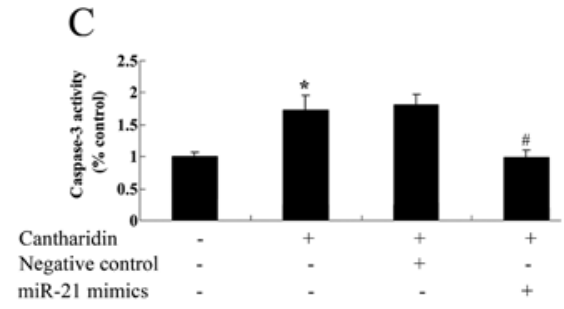

F

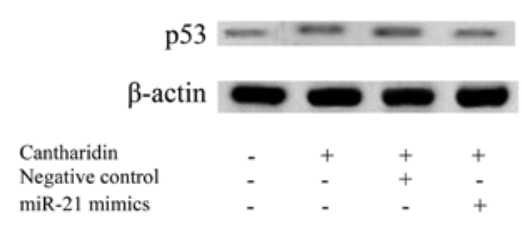

G

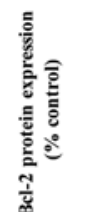

Cantharidin

Negative control

miR-21 mimics

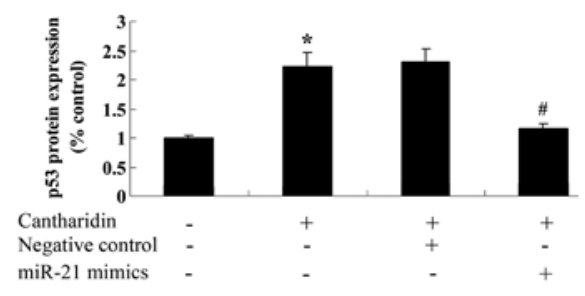

$\mathrm{H}$

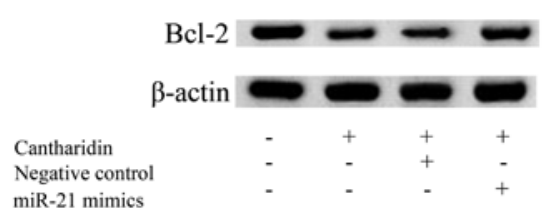

I

Figure 10. Overexpression of miR-214 and the anticancer effect of cantharidin on TSCC Tca8113 cells. Following treatment with cantharidin (20 $\mu \mathrm{M})$ for 48 h, miR-214 mimics induced (A) miR-214 expression, (B) promoted cell proliferation, and (C) inhibited caspase-3 activity. (D, F and G) p53, Bcl-2 and Bax protein expression by western blot analysis. (E, H and I) Statistical analysis of p53, Bcl-2 and Bax protein expression levels of TSCC Tca8113 cells. * $\mathrm{P}<0.01$ compared with $0 \mu \mathrm{M}$ cantharidin treatment group. ${ }^{\#} \mathrm{P}<0.01$ compared with the cantharidin treatment group transfected with negative control. TSCC, tongue squamous cell carcinoma.

treatment with cantharidin significantly inhibited the proliferation and increased cytotoxicity of TSCC Tca8113 cells in a dose- and time-dependent manner. Cantharidin also stimulated cell apoptosis and enhanced caspase-9/3 activities of TSCC Tca8113 cells. The results were in concordance with those of other studies. For example, Zhang et al suggested that cantharidin induced apoptosis by activating caspase-3, -7, -8 and -9 in human gastric cancer (19). Hsia et al reported that cantharidin induces apoptosis by activating caspase-3 and - 8 in H460 human lung cancer cells (22). Therefore, cantharidin is an optimal potential therapeutic agent for TSCC.

Results of miRNAs studies have identified that a large number of miRNAs with abnormal expressions regulate the development of various types of cancer including pancreatic cancer by regulating the expression of target genes. Thus, large-scale screening of the abnormal expression of miRNAs in the tumor development process may provide a comprehensive understanding of the biological characteristics of tumor in human (23). Findings of a recent study showed that miR-214 is abnormally expressed in a variety of malignancies. However, the expression in different tumors are not the same, with certain specificity (24). We found that cantharidin decreased the miR-214 expression levels of Tca8113 cells. This result was consistent with that of the study by Lu et al whereby cantharidin exerted an anticancer effect by miR-214 modulating in hepatocellular carcinoma (8). However, the detailed mechanisms on how cantharidin regulates miR-214 expression remain to be determined in future studies.
The p53 tumor-suppressor gene has been extensively studied. The p53 gene is a tumor-suppressor gene that is associated with human cancer and plays an important role in the regulation of the cell cycle (25). Its product, p53 protein, inhibits tumorigenesis, although following gene mutation the p53 protein loses its tumor-suppressor effect, with the promotion of the activity of malignancy (26). In the present study, we found that treatment with cantharidin effectively activated p53 protein expression of Tca8113 cells. Hsia et al showed that cantharidin inhibited DNA repair-associated protein levels (p53 and H2A.X) and induced DNA damage in NCI-H460 human lung cancer cells (18). Kuo et al reported that cantharidin induced the apoptosis of human bladder cancer by promoting the p53 level (27).

Apoptosis is a type of cell death with specific morphological change, which is a physiological process caused by a series of gene actions. Bcl-2 oncogene is a cancer gene found at $\mathrm{t}(14 ; 18)$ chromosomal translocation breakpoint, of which the overexpression protects tumor cells from apoptosis (28). Cantharidin reduced the $\mathrm{Bcl}-2$ protein expression and activated the Bax protein expression of Tca8113 cells in the present study. Li et al suggested that cantharidin induced oxidative stress-independent growth inhibition of pancreatic cancer cells through suppression of the expression of antiapoptotic Bcl-2 (29). These findings suggested cantharidin induced apoptosis via Bcl-2/Bax in human bladder carcinoma (30), pulmonary carcinoma (31), and pancreatic cancer (29) cells. 
The present study has limitations. To clarify the mechanism involved in the suppression of Tca8113 cells, the effect of cantharidin on miR-214, p53 and Bcl-2/Bax expression was examined. We found that the miR-214 silence expression stimulated the p53 protein expression and inhibited the Bcl-2/Bax signaling pathway in Tca8113 cells. Additionally, miR-451 overexpression reversed the anticancer effect of cantharidin on TSCC Tca8113 cella, attenuated p53 protein and stiumlated the Bcl-2/Bax signaling pathway in TSCC Tca8113 cells. With respect to the anticancer effect of cantharidin on TSCC and its mechanism, further studies on knockdown of miR-214 may provide more information for an improved understanding of the effect of cantharidin affected by p53 and Bcl-2/Bax signal on the proliferation and apoptosis in TSCC.

In conclusion, the results show the anticancer effect of cantharidin inhibits cell proliferation and promotes apoptosis of TSCC. Knockdown of miR-214 activates the effect of cantharidin on cell proliferation and apoptosis in vivo. Our findings suggest that cantharidin is an important potential therapeutic agent in TSCC and a potential therapeutic target for TSCC patients.

\section{Acknowledgements}

The present study was supported by the National Natural Science Foundation of China (no. 31101042).

\section{References}

1. Shao Y, Sha XY, Bai YX, Quan F and Wu SL: Effect of A disintegrin and metalloproteinase 10 gene silencing on the proliferation invasion and migration of the human tongue squamous cell carcinoma cell line TCA8113. Mol Med Rep 11: 212-218, 2015.

2. Li H, Huang D, Gao Z, Chen Y, Zhang L and Zheng J: Scutellarin inhibits the growth and invasion of human tongue squamous carcinoma through the inhibition of matrix metalloproteinase- 2 and -9 and $\alpha v \beta 6$ integrin. Int J Oncol 42: 1674-1681, 2013.

3. Addeo R, Napolitano A, Montella L and Ricciardiello F: Squamous cell carcinoma of the tongue in a female with advanced breast cancer: A case report of an elderly patient presenting with two types of cancer. Oncol Lett 8: 235-237, 2014.

4. Chiyomaru T, Seki N, Inoguchi S, Ishihara T, Mataki H, Matsushita R, Goto Y, Nishikawa R, Tatarano S, Itesako T, et al: Dual regulation of receptor tyrosine kinase genes EGFR and $c$-Met by the tumor-suppressive microRNA-23b/27b cluster in bladder cancer. Int J Oncol 46: 487-496, 2015.

5. Jin D, Fang Y, Li Z, Chen Z and Xiang J: Epithelial-mesenchymal transition-associated microRNAs in colorectal cancer and drugtargeted therapies (Review). Oncol Rep 33: 515-525, 2015.

6. Yu ZW, Zhong LP, Ji T, Zhang P, Chen WT and Zhang CP: MicroRNAs contribute to the chemoresistance of cisplatin in tongue squamous cell carcinoma lines. Oral Oncol 46: 317-322, 2010.

7. Zhang ZC, Li YY, Wang HY, Fu S, Wang XP, Zeng MS, Zeng YX and Shao JY: Knockdown of miR-214 promotes apoptosis and inhibits cell proliferation in nasopharyngeal carcinoma. PLoS One 9: e86149, 2014.

8. Lu S, Gao Y, Huang X and Wang X: Cantharidin exerts antihepatocellular carcinoma by miR-214 modulating macrophage polarization. Int J Biol Sci 10: 415-425, 2014.

9. Ozaki T and Nakagawara A: p53: The attractive tumor suppressor in the cancer research field. J Biomed Biotechnol 2011: 603925, 2011.

10. Qi L and Zhang Y: Alisertib (MLN8237), a selective Aurora-A kinase inhibitor, induces apoptosis in human tongue squamous cell carcinoma cell both in vitro and in vivo. Tumour Biol: Nov 4, 2014 (Epub ahead of print).

11. Yasumoto J, Imai Y, Takahashi A, Ohnishi K, Yuki K, Kirita T and Ohnishi T: Analysis of apoptosis-related gene expression after X-ray irradiation in human tongue squamous cell carcinoma cells harboring wild-type or mutated $p 53$ gene. J Radiat Res 44: 41-45, 2003.
12. Nagler RM, Kerner H, Laufer D, Ben-Eliezer S, Minkov I and Ben-Itzhak O: Squamous cell carcinoma of the tongue: The prevalence and prognostic roles of p53, Bcl-2, c-erbB-2 and apoptotic rate as related to clinical and pathological characteristics in a retrospective study. Cancer Lett 186: 137-150, 2002.

13. Niu XW, Feng J, Peng ZH, et al: Receptor-related mechanism of proliferation inhibilion and apoptosis induetion of human tongue squamous cell line Tca8113 by retinoids. Di Yi Jun Yi Da Xue Xue Bao 25: 935-941, 2005.

14. Saleh HA, Jackson H, Khatib G and Banerjee M: Correlation of bcl-2 oncoprotein immunohistochemical expression with proliferation index and histopathologic parameters in colorectal neoplasia. Pathol Oncol Res 5: 273-279, 1999.

15. Xie X, Clausen OP, De Angelis P and Boysen M: The prognostic value of spontaneous apoptosis, $\mathrm{Bax}, \mathrm{Bcl}-2$, and $\mathrm{p} 53$ in oral squamous cell carcinoma of the tongue. Cancer 86: 913-920, 1999.

16. Yeh CB, Su CJ, Hwang JM and Chou MC: Therapeutic effects of cantharidin analogues without bridging ether oxygen on human hepatocellular carcinoma cells. Eur J Med Chem 45: 3981-3985, 2010.

17. Barr AC, Wigle WL, Flory W, Alldredge BE and Reagor JC: Cantharidin poisoning of emu chicks by ingestion of Pyrota insulata. J Vet Diagn Invest 10: 77-79, 1998.

18. Hsia TC, Lin JH, Hsu SC, Tang NY, Lu HF, Wu SH, Lin JG and Chung JG: Cantharidin induces DNA damage and inhibits DNA repair-associated protein levels in NCI-H460 human lung cancer cells. Environ Toxicol: Mar 17, 2014 (Epub ahead of print). doi: 10.1002/tox.21986.

19. Zhang C, Chen Z, Zhou X, Xu W, Wang G, Tang X, Luo L, Tu J, Zhu Y, Hu W, et al: Cantharidin induces $\mathrm{G}_{2} / \mathrm{M}$ phase arrest and apoptosis in human gastric cancer SGC-7901 and BGC-823 cells. Oncol Lett 8: 2721-2726, 2014.

20. Wang K, Lin C, Wang C, Shao Q, Gao W, Song B, Wang L, Song X, Qu X and Wei F: Silencing Kif2a induces apoptosis in squamous cell carcinoma of the oral tongue through inhibition of the PI3K/Akt signaling pathway. Mol Med Rep 9: 273-278, 2014.

21. Fang QG, Shi S, Liu FY and Sun CF: Tongue squamous cell carcinoma as a possible distinct entity in patients under 40 years old. Oncol Lett 7: 2099-2102, 2014.

22. Hsia TC, Yu CC, Hsu SC, Tang NY, Lu HF, Huang YP, Wu SH, Lin JG and Chung JG: Cantharidin induces apoptosis of H460 human lung cancer cells through mitochondria-dependent pathways. Int J Oncol 45: 245-254, 2014.

23. Su Y, Ni Z, Wang G, Cui J, Wei C, Wang J, Yang Q, Xu Y and Li F: Aberrant expression of microRNAs in gastric cancer and biological significance of miR-574-3p. Int Immunopharmacol 13: 468-475, 2012 .

24. Liu M, Liu J, Wang L, Wu H, Zhou C, Zhu H, Xu N and Xie Y: Association of serum microRNA expression in hepatocellular carcinomas treated with transarterial chemoembolization and patient survival. PLoS One 9: e109347, 2014.

25. Lee HP, Li TM, Tsao JY, Fong YC and Tang CH: Curcumin induces cell apoptosis in human chondrosarcoma through extrinsic death receptor pathway. Int Immunopharmacol 13: 163-169, 2012.

26. Marx J: New tumor suppressor may rival p53. Science 264: 344-345, 1994.

27. Kuo JH, Chu YL, Yang JS, Lin JP, Lai KC, Kuo HM, Hsia TC and Chung JG: Cantharidin induces apoptosis in human bladder cancer TSGH 8301 cells through mitochondria-dependent signal pathways. Int J Oncol 37: 1243-1250, 2010.

28. Saigusa S, Inoue Y, Tanaka K, Okugawa Y, Toiyama Y, Uchida K, Mohri Y and Kusunoki M: Lack of M30 expression correlates with factors reflecting tumor progression in rectal cancer with preoperative chemoradiotherapy. Mol Clin Oncol 2: 99-104, 2014.

29. Li W, Xie L, Chen Z, Zhu Y, Sun Y, Miao Y, Xu Z and Han X: Cantharidin, a potent and selective PP2A inhibitor, induces an oxidative stress-independent growth inhibition of pancreatic cancer cells through G2/M cell-cycle arrest and apoptosis. Cancer Sci 101: 1226-1233, 2010.

30. Huan SK, Lee HH, Liu DZ, Wu CC and Wang CC: Cantharidininduced cytotoxicity and cyclooxygenase 2 expression in human bladder carcinoma cell line. Toxicology 223: 136-143, 2006.

31. Zhang WD, Zhao HR, Yan Y, Wang XH, Zong ZH and Liu Y: Apoptosis induced by cantharidin in human pulmonary carcinoma cells A549 and its molecular mechanisms. Zhonghua Zhong Liu Za Zhi 27: 330-334, 2005. 